\title{
TITLE:
}

\section{Kinetic analysis of color changes in cellulose during heat treatment}

$\operatorname{AUTHOR}(S)$ :

Matsuo, Miyuki; Umemura, Kenji; Kawai, Shuichi

CITATION:

Matsuo, Miyuki ...[et al]. Kinetic analysis of color changes in cellulose during heat treatment. Journal of Wood Science 2012, 58(2): 113-119

ISSUE DATE:

2012-04

URL:

http://hdl.handle.net/2433/156046

\section{RIGHT:}

The final publication is available at www.springerlink.com; この論文は 出版社版でありません。引用の際には出版社版をご確認ご利用くださ $\iota_{\circ}$; This is not the published version. Please cite only the published version. 
Miyuki MATSUO, Kenji UMEMURA, Shuichi KAWAI (2012) Kinetic analysis of color changes in cellulose during heat treatment, Journal of Wood Science, 58(2), 113-119, DOI: $10.1007 / \mathrm{s} 10086-011-1235-5$

\title{
Kinetic analysis of color changes in cellulose during heat treatment
}

\author{
Miyuki MATSUO ${ }^{1, *}$, Kenji UMEMURA ${ }^{1}$, Shuichi KAWAI ${ }^{1}$ \\ ${ }^{1}$ Research Institute for Sustainable Humanosphere, Kyoto University \\ Gokasho, Uji, Kyoto, Japan 611-0011 \\ *E-mail: matsuomiyuki@ rish.kyoto-u.ac.jp
}

\section{keywords}

cellulose; heat treatment; color; kinetic analysis

A part of this work was presented at the International Conference of COST Action IE0601, "Wood Science for Conservation of Cultural Heritage", 2009, and the $61^{\text {st }}$ annual meeting of the Japan Wood Research Society.

\begin{abstract}
This paper deals with the kinetics on the color changes of cellulose during heat treatment. The color of cellulose heated at $90-180^{\circ} \mathrm{C}$ was measured by a spectrophotometer and expressed by CIELAB color parameters. The values of $L^{*}$ decreased and those of $a^{*}, b^{*}$ and $\Delta E^{*}{ }_{a b}$ increased at all the treatment temperatures. Several kinetic models, namely, the zero-order, first-order, second-order and autocatalytic model, were applied to the changes in the color values. Furthermore, the results of kinetic analysis using the best-fit model were compared to the results obtained from conventional kinetic models. It was suggested that the kinetic analysis using the best-fit model was the better way to accurately predict color changes during heat treatment. The values of apparent activation energy calculated from the changes of $L^{*}, a^{*}, b^{*}$ and $\Delta E^{*}{ }_{a b}$ were $125,124,118$ and $120 \mathrm{~kJ} / \mathrm{mol}$, respectively. These values were similar to the reported values calculated from other chemical or mechanical properties.
\end{abstract}


Matsuo et al. (2012) Journal of Wood Science, 58(2), 113-119, Authors' copy

\section{Introduction}

Cellulose is the major component of ligno-cellulosic materials such as paper, textile and wood, and the chemical and mechanical degradation of cellulose has a great influence on the degradation of ligno-cellulosic materials. Kinetic study has been of great importance not only for understanding the degradation mechanism but also for predicting the degradation of chemical and mechanical properties. Numerous kinetic studies on cellulose have been reported by using thermally and hygrothermally treated cellulose, mainly focusing on the degradation of electrical insulation paper in electrical power transformers ${ }^{1,2}$ and the degradation of acidic paper, which has been widely used from the $18^{\text {th }}$ century and has caused catastrophic degradation of books and documents. ${ }^{3-5}$ The degradation of cellulose has been widely elucidated by weight decrease, degree of polymerization (DP), mechanical properties, crystallinity and morphological characteristics. In addition, the color difference and the yellowing index are also used. ${ }^{6,7}$ In the field of paper and textile science, the change in color of cellulose is important not only from an aesthetic point of view but also as a possible index of the degradation of materials. ${ }^{8}$ Several investigations have reported a correlation between color parameters and either DP or mechanical properties. ${ }^{9-11}$ Color measurement is non-destructive and only requires a small area, unlike the measurements of chemical and mechanical properties. Therefore, color measurement is also suitable when the aesthetic aspects of measuring objects are important and destructive tests are unacceptable, for example, for the investigation of culturally significant properties or the quality monitoring in industrial processing.

The color of cellulose turns brown or yellow during heat treatment. ${ }^{11,12}$ However, the mechanism of this change has not been clarified yet and only a few reports were found in kinetic analysis based on the color changes of cellulose. ${ }^{13}$

This study examines the color changes of cellulose during heat treatment in order to elucidate and predict desirable/undesirable color changes of ligno-cellulosic materials. For an accurate analysis, we have applied several kinetic models and a best-fit model employing a kinetic approach based on the time-temperature superposition (TTSP) method.

\section{Materials and methods}

\subsection{Materials}

Whatman No.1 cellulose filter paper was used as a cellulose sample. The basic information of the samples is summarized in Table 1 . Specimens of approximately $20 \mathrm{~mm} \times 40 \mathrm{~mm}$ were dried in an air-circulating oven and then in a vacuum oven at $60^{\circ} \mathrm{C}$ for 24 hours each. The low drying temperature was set to avoid undesirable reactions of cellulose. Each dried specimen was heated in an air-circulating oven at 4 temperature levels from $90^{\circ} \mathrm{C}$ to $180^{\circ} \mathrm{C}$ for a duration ranging from an hour to approximately 1.8 years. Table 2 shows the treatment times of the specimens at each treatment temperature. They were planned under the assumption that a $10^{\circ} \mathrm{C}$ increase of the reaction temperature halves the reaction time to obtain a similar intensity of reaction among the treatment of different temperatures. ${ }^{14}$ The treatment at $90^{\circ} \mathrm{C}$ is now in process with the planned treatment time 
Matsuo et al. (2012) Journal of Wood Science, 58(2), 113-119, Authors' copy

shown in parentheses in Table 2.

\section{Table 1}

The basic information of the cellulose sample and the average initial color values with their standard deviations in parentheses.

\begin{tabular}{|c|c|c|c|c|c|c|}
\hline Trade name & $\begin{array}{l}\text { Ash } \\
\text { content [\%] }\end{array}$ & $\begin{array}{l}\text { Basis } \\
\text { weight } \\
{\left[\mathrm{g} / \mathrm{m}^{2}\right]}\end{array}$ & $\begin{array}{l}\text { Degree of } \\
\text { polymerization }\end{array}$ & $L_{0} *$ & $a_{0} *$ & $b_{0}^{*}$ \\
\hline Whatman No.1 & $<0.06^{1)}$ & $87^{1)}$ & $500-5000^{2)}$ & $98.11(0.01)$ & $-0.02(0.01)$ & $2.31(0.06)$ \\
\hline
\end{tabular}

\section{Table 2}

Treatment temperatures and times of cellulose samples. The treatment at $90^{\circ} \mathrm{C}$ is now in process with the planned treatment time in parentheses.

\begin{tabular}{l|llll}
\hline & $90^{\circ} \mathrm{C}$ & $120^{\circ} \mathrm{C}$ & $150^{\circ} \mathrm{C}$ & $180^{\circ} \mathrm{C}$ \\
\hline & & 64 & 8 & 1 \\
& 768 & & & \\
& & & 16 & 2 \\
Treatment & 1560 & 192 & 24 & 3 \\
time [hour] & 2560 & 320 & 40 & \\
& 3584 & 448 & 56 & 7 \\
& 12288 & 1536 & 192 & 24 \\
& 15580 & 3096 & 384 & 48 \\
& $(24576)$ & 5450 & 672 & \\
& $(43008)$ & 7680 & 960 & 120 \\
& $(61440)$ & & 1280 & \\
& & & & 240 \\
& & & 2304 & 288 \\
& & & 2768 & 336 \\
\hline
\end{tabular}

\subsection{Color measurement}

The color of the specimens was measured with a spectrophotometer (KONICA MINOLTA CM-2600d) under a D65 light source and an observed angle of $10^{\circ}$. The sensor head of the spectrophotometer was $8 \mathrm{~mm}$ in diameter. The size of paper specimens was sufficiently large relative to the sensor head. The CIELAB color parameters $\left(L^{*}, a^{*}\right.$ and $\left.b^{*}\right)$ were used to express the color 
changes. The differences in parameters $\Delta L^{*}, \Delta a^{*}$ and $\Delta b^{*}$ and the total color differences $\Delta E^{*}{ }_{a b}$ were calculated using the following formulas: ${ }^{19,20}$

$$
\begin{aligned}
& \Delta L^{*}=L^{*}-L_{0} * \\
& \Delta a^{*}=a^{*}-a_{0} * \\
& \Delta b^{*}=b^{*}-b_{0} * \\
& \Delta E_{a b}=\sqrt{\Delta L^{* 2}+\Delta a^{* 2}+\Delta b^{* 2},}
\end{aligned}
$$

where $L^{*}$ is the lightness and $a^{*}$ and $b^{*}$ are the color coordinates under any testing condition, respectively, and $L_{0} *, a_{0} *$ and $b_{0} *$ are the corresponding reference values obtained as the average of untreated specimens shown in Table 1, respectively. The color values of 3 specimens were averaged and the standard deviations were also calculated. The average of the coefficients of variation for each treatment condition were $0.23 \%, 2.70 \%, 1.38 \%$ and $1.89 \%$ for $L^{*}, a^{*}, b^{*}$ and $\Delta E^{*}{ }_{a b}$, respectively. Since the variation in the color values was negligibly small, the error bars displaying standard deviations were not drawn in the following figures.

The specimen preparation and the color measurement were always performed using rubber gloves.

\subsection{Weight reduction}

The sample amount for each condition was approximately $3 \mathrm{~g}$, which was measured before and after heat treatment under the dry condition. The weight reductions were calculated based on the following equation:

Weight reduction $=100 \times \frac{W_{0}-W_{t}}{W_{0}}[\%]$,

where $W_{0}$ and $W_{t}$ are the dry weight of cellulose before treatment and at treatment time $t$, respectively.

\subsection{Kinetic analysis for color changes of cellulose}

Numerous reports have discussed the applicability of kinetic models, especially with respect to the degree of polymerization and some mechanical properties. ${ }^{21,22}$ However, there have been few reports dealing with the kinetic analysis of color properties. ${ }^{13}$

The rate of change of a material property $P$ at time $t$ can be represented by:

$\frac{\mathrm{d} P}{\mathrm{~d} t}= \pm k P^{n}$,

where $n$ is the order of reaction.

By integrating Eq. (4), the zero-order (Eq. 5), first-order (Eq. 6) and second-order (Eq. 7) kinetic models can be derived as:

$P=P_{0} \pm k t$

$P=P_{0} \exp ( \pm k t)$ 
Matsuo et al. (2012) Journal of Wood Science, 58(2), 113-119, Authors' copy

$P=\frac{P_{0}}{1 \pm k t P_{0}}$

where $P$ is the color value at a treatment time $t, P_{0}$ the initial value of color, and $k$ the rate constant of the chemical reaction. Many cellulose degradation kinetics have been based on these reaction models. Zervos et al. ${ }^{13}$ reported that a kinetic model based on autocatalysis (Eq. 8) fitted well the changes of $L^{*}$ and $b^{*}$ during the heat treatment in sealed vessels:

$P=P_{0} \pm C\left(2^{k t}-1\right)$,

where $C$ is constant.

In general, it is known that a chemical reaction can be described by the Arrhenius equation:

$$
k=A \exp \left(-\frac{E_{\mathrm{a}}}{R T}\right) \text {, }
$$

where $A$ is the frequency factor, $E_{\mathrm{a}}$ the apparent activation energy, $R$ the gas constant, and $T$ the absolute temperature of the reaction. The apparent activation energy is then obtained from the slope of the Arrhenius plot, which is the logarithm of $k$ versus the reciprocal of $T^{23}$

To determine the activation energy more accurately, a time-temperature superposition (TTSP) method has been proposed. ${ }^{24-27}$ An Arrhenius approach applying the TTSP method is briefly described below. When the measured material property is plotted as a function of logarithmic treatment time at different temperatures, the shift distance used to superpose the plotted curves to the curves at a fixed reference temperature $T_{\text {ref }}$ along the logarithmic time axis is called the time-temperature shift factor $a_{T}$, and is given as:

$$
a_{T}=\frac{t_{T}}{t_{\text {ref }}}
$$

where $t_{\text {ref }}$ is the test time at $T_{\text {ref, }}$ and $t_{T}$ is the time required to give the same response at the test temperature $T$. Combining Eqs. (9) and (10) gives:

$a_{T}=\exp \left[\frac{E_{a}}{R}\left(\frac{1}{T}-\frac{1}{T_{\text {ref }}}\right)\right]$,

where both $T$ and $T_{\text {ref }}$ are absolute temperatures. Plotting $\ln \left(a_{T}\right)$ vs. 1/T is another way to calculate $E_{\mathrm{a}}$. Data analysis was performed using the FlexPro 8 software package (Weisang GmbH, Germany). All parameters of the model functions and the values of $a_{T}$ were estimated using a non-linear iterative curve-fitting method. The coefficient of determination $\left(R^{2}\right)$ and the root mean square error (RSME) were used as the criteria to express the fitting of the tested models to the experimental data:

$$
R^{2}=\frac{\sum_{i=1}^{N}\left(\hat{Y}_{i}-\bar{Y}\right)^{2}}{\sum_{i=1}^{N}\left(Y_{i}-\bar{Y}\right)^{2}}
$$


Matsuo et al. (2012) Journal of Wood Science, 58(2), 113-119, Authors' copy

$\mathrm{RSME}=\sqrt{\frac{\sum_{i=1}^{N}\left(Y_{i}-\hat{Y}_{i}\right)}{N}}$,

where $\hat{Y}_{i}$ and $Y_{i}$ are the measured and modeled values, respectively, $\bar{Y}$ is the average of the measured data and $N$ is the total number of observations. The higher the value of $R^{2}$ and the lower the value of RSME, the better the model fits the data.

\section{Results and discussion}

\subsection{Color changes of cellulose during heat treatment}

As shown in the representative specimen presented in Figure 1, the color of cellulose turned brown and dark with increasing treatment time. Figure 2 shows the changes of the color parameters according to the duration and temperature of treatment. The decrease in $L^{*}$ at all temperatures indicates that the specimens became darker with increasing treatment time. The increases in $a^{*}$ and $b^{*}$ indicate that the specimens became more red and yellow. These results corresponded to the increase in $\Delta E^{*}{ }_{a b}$. Similar behavior irrespective of treatment temperatures suggested that the same reaction processes might cause the color changes, irrespective of temperatures.

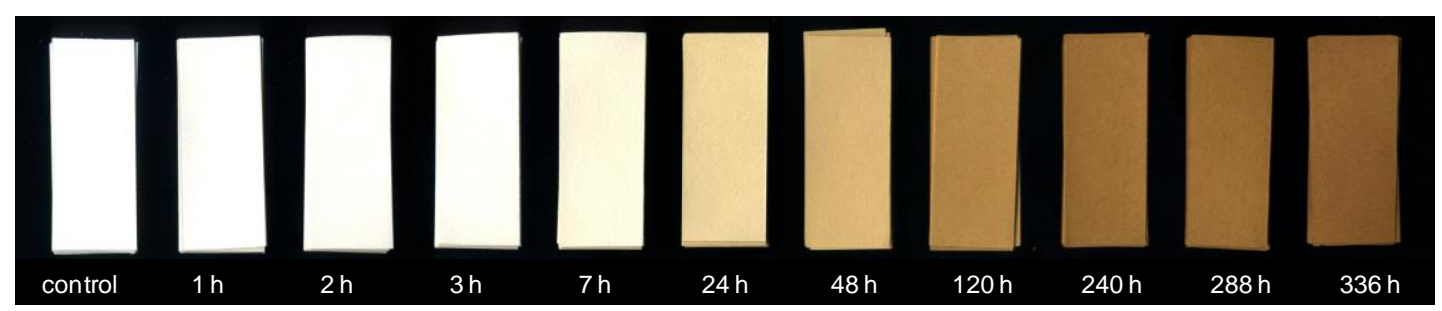

Figure 1

Cellulose specimens treated at $180^{\circ} \mathrm{C}$ with the treatment time (h). 
Matsuo et al. (2012) Journal of Wood Science, 58(2), 113-119, Authors' copy
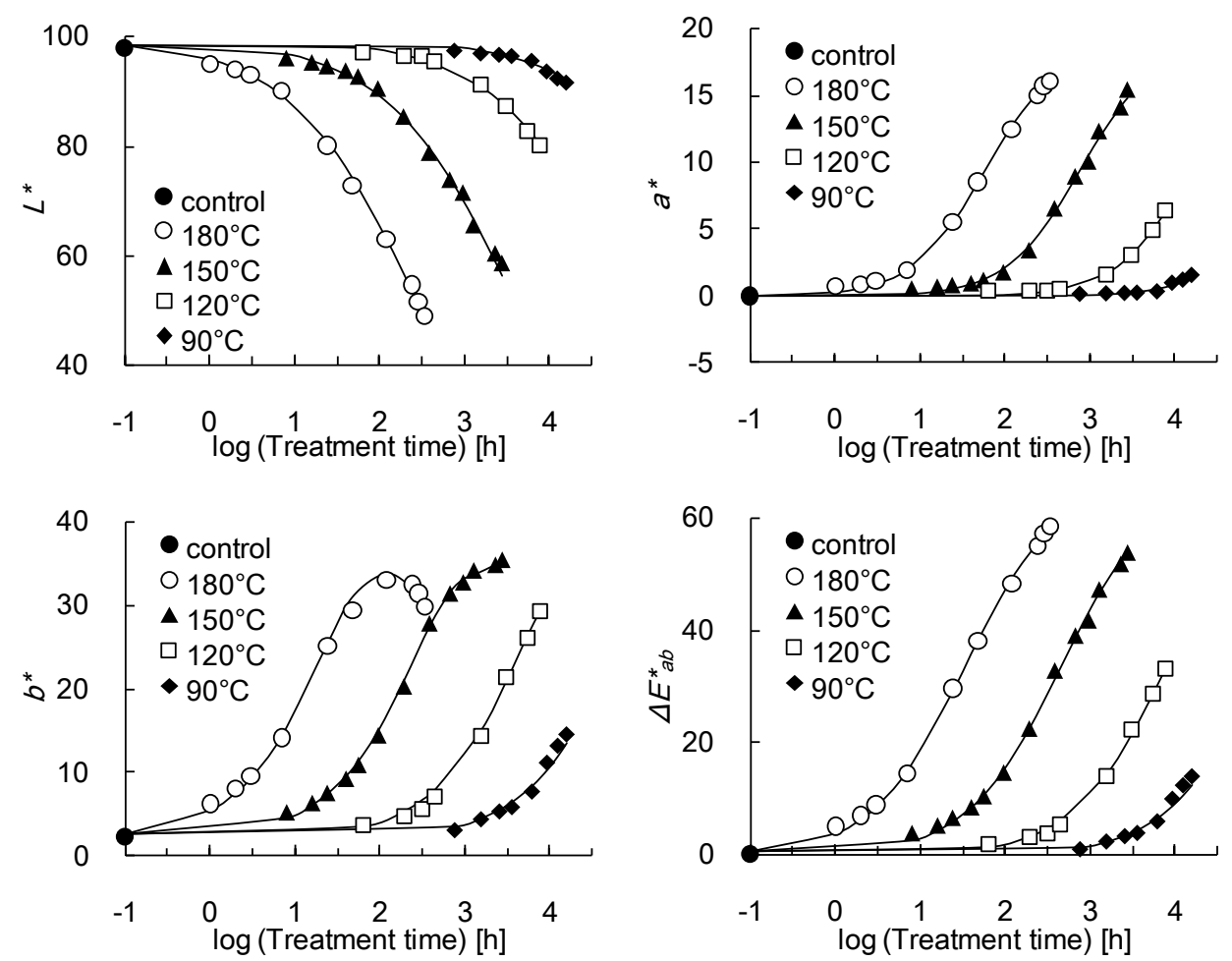

Figure 2

Changes in $L^{*}, a^{*}, b^{*}$, and $\Delta E^{*}{ }_{a b}$ during heat treatment as a function of time.

\subsection{Kinetic analysis of the color changes of cellulose}

Several kinetic models were applied to the experimental data. In addition, in an analysis independent of these models, the function giving the best fit was selected. Since a similar behavior was observed irrespective of treatment temperatures, the data from the $180^{\circ} \mathrm{C}$-treatment were used to determine the best-fit model.

Judging from the values of $R^{2}$ and RSME, the autocatalytic model fit the color changes well in all color parameters, while the zero-, first- and second-order kinetic models did not fit the color parameters well except in the case of $L^{*}$.

As the function giving the best fit for all color parameters, the NIST Hahn1 model was selected:

$P=\frac{C_{0}+C_{1} t+C_{2} t^{2}+C_{3} t^{3}}{1+C_{4} t+C_{5} t^{2}+C_{6} t^{3}}$,

where $C_{i}(i=0, \ldots, 6)$ is constant. However, it should be noted that we only used this function to numerically analyze the color changes. Thus, the function might have no meaning in terms of the reaction mechanism. The obtained values of $R^{2}$ and RSME for each model are summarized in Table 3.

From the results obtained above, the Arrhenius plots were described by using the autocatalytic model and the best-fit model. Figure 3 shows the autocatalytic model fitted to the changes in $\Delta E^{*}{ }_{a b}$ at each temperature. High values of $R^{2}$ were obtained for all treatment temperatures $\left(R^{2}>0.988\right)$. However, in spite of the high values of $R^{2}$, the experimental data deviated from the saturation of sigmoidal curve 


\section{Matsuo et al. (2012) Journal of Wood Science, 58(2), 113-119, Authors' copy}

characteristic with the autocatalytic model as shown in figure 3 and the autocatalytic reaction is not likely to occur in the ventilated conditions as in the studies like ours. ${ }^{22,28}$ By using the rate constant $k$ of each color parameter at each temperature calculated according to Eq. (8), the activation energy $E_{\text {a }}$ was calculated from Eq. (9). The values of $E_{\mathrm{a}}$ ranged from 101 to $125 \mathrm{~kJ} / \mathrm{mol}$, as shown in Table 4 . Figure 4 shows the data superposed to the best-fit model by using $a_{T}$ at each treatment temperature. The regression and the superposition fit the data set extremely well $\left(R^{2}>0.998\right)$. The activation energy $E_{\mathrm{a}}$ was calculated according to Eq. (11) and the values of $E_{\mathrm{a}}$ ranged from 118 to $125 \mathrm{~kJ} / \mathrm{mol}$. The values of $E_{\mathrm{a}}$ for $L^{*}$ and $\Delta E^{*}{ }_{a b}$ calculated from the autocatalytic model were approximately $20 \mathrm{~kJ} / \mathrm{mol}$ smaller than those calculated from the best-fit model. This may be because the experimental data were a little outside the range of autocatalytic model under the present experimental conditions, as mentioned above. Therefore, it is better to use the best-fit model with the TTSP method to accurately predict the color changes during heat treatment.

Figure 5 shows the Arrhenius plots of $\Delta E^{*}{ }_{a b}$ and their linear regression line as an example by using the best-fit model. The regression lines for Arrhenius plots showed a good linearity for all color parameters $\left(R^{2}>0.987\right)$, suggesting that kinetic analysis can be applied to cellulose color properties and the prediction of color changes. The results also suggested that the color changes during heat treatment at the temperatures ranging from $90^{\circ} \mathrm{C}$ to $180^{\circ} \mathrm{C}$ can be explained as the same reaction mechanism, presumably thermal oxidation, which occurs in the presence of oxygen and the absence of moisture. The values of $E_{\mathrm{a}}$ calculated from the color parameters were similar to the reported values obtained from the other properties of cellulose, such as the degree of polymerization and mechanical properties..$^{14,21,24,29}$ However, these reported values have wide variation and are still controversial. $^{21}$

Figure 6 shows the weight reduction as a function of time. The weight was reduced with increasing time at $120^{\circ} \mathrm{C}, 150^{\circ} \mathrm{C}$, and $180^{\circ} \mathrm{C}$ and slightly reduced at $90^{\circ} \mathrm{C}$. As shown in the representative case in Figure 7, the color changed drastically before the remarkable weight reduction started, indicating that the color changes of cellulose are mainly due to the denaturation of cellulose and/or a slight amount of decomposition products of cellulose rather than the major decomposition of cellulose. The factors responsible for the color changes of cellulose were estimated to be carbonyl groups in the cellulose chains and the formation of colored low-molecular substances such as furan-type compounds. ${ }^{10,30}$ Łojewski et al. ${ }^{9}$ reported that the increase of $\Delta E^{*}{ }_{a b}$ had a significant linear relationship with the amount of furfural formed during heat treatment of cellulose at $90^{\circ} \mathrm{C}$. Matsuoka et al. ${ }^{31,32}$ concluded that colored substances were formed at the reducing ends of cellulose during heat treatment at $60-280^{\circ} \mathrm{C}$. These results suggested that the color changes were due to the denaturation of the reducing ends, the formation of furan-type compounds, or a combination of both these effects. The results obtained from this study will contribute to a better understanding of the degradation of cellulose and provide further evidence of the effectiveness of color parameters as an index of cellulose degradation.

The contributions of cellulose to color changes of ligno-cellulosic materials were estimated by 
Matsuo et al. (2012) Journal of Wood Science, 58(2), 113-119, Authors' copy

comparing them to color changes of hinoki (Chamaecyparis obtusa Endl.) wood which was treated and analyzed in almost the same conditions and procedures with the present study. ${ }^{33}$ The values of $L^{*}$ decreased and $a^{*}, b^{*}$ and $\Delta E^{*}{ }_{a b}$ increased both in cellulose and wood. But in the later reaction stages of hinoki wood, the values of $a^{*}$ and $b^{*}$ started to decrease. The increase and subsequent decrease of $a^{*}$ and $b^{*}$ were also observed in the other wood species. ${ }^{34,35}$ The changes in $L^{*}$ and $\Delta E^{*}{ }_{a b}$ of hinoki wood were similar degree to those of cellulose. These results show that cellulose is a major component that contributes to color changes of wood, however, other wood components such as extractives, lignin, hemicelluloses and minor components also have effects on color changes of wood, especially on the chromatic characteristics. The successful kinetic analysis indicated that the thermal oxidation might cause the color changes of wood as well as cellulose, irrespective of treatment temperatures. The values of activation energy calculated from each color parameters of wood were lower than those of cellulose in all color parameters. The lower activation energy may be due to wood components other than cellulose. While color changes of ligno-cellulosic materials are due to the multiple and/or interactive effect of their components, the color changes of cellulose certainly contributes to that of ligno-cellulosic materials.

\section{Table 3}

Comparison of coefficients of determination $\left(R^{2}\right)$ and root mean square errors $(R M S E)$ of regression curves among several kinetic models and a best-fit model to changes in the color values during the treatment at $180^{\circ} \mathrm{C}$.

\begin{tabular}{lllllllllll}
\hline & zero-order & \multicolumn{2}{l}{ first-order } & \multicolumn{2}{l}{ second-order } & \multicolumn{2}{l}{ autocatalytic } & \multicolumn{2}{l}{ best fit* } \\
\cline { 2 - 12 } & $R^{2}$ & $R M S E$ & $R^{2}$ & $R M S E$ & $R^{2}$ & $R M S E$ & $R^{2}$ & $R M S E$ & $R^{2}$ & $R M S E$ \\
\hline$L^{*}$ & 0.8846 & 6.201 & 0.9226 & 5.174 & 0.9533 & 4.068 & 0.9892 & 1.901 & $\underline{0.9999}$ & $\underline{0.138}$ \\
$a^{*}$ & 0.8665 & 2.325 & 0.7206 & 3.190 & 0.5660 & 3.824 & $\underline{0.9970}$ & $\underline{0.351}$ & $\underline{0.9998}$ & $\underline{0.088}$ \\
$b^{*}$ & 0.5408 & 7.816 & 0.4369 & 8.403 & 0.3541 & 8.837 & $\underline{0.9924}$ & 1.005 & $\underline{0.9996}$ & $\underline{0.226}$ \\
$\Delta E^{*}{ }_{a b}$ & 0.7942 & 9.987 & 0.6683 & 12.141 & 0.5433 & 13.782 & 0.9878 & 2.429 & $\underline{0.9999}$ & $\underline{0.205}$ \\
\hline
\end{tabular}

* Eq.(14) was used as a best fit model.

Underlined values are above 0.9900 in $R^{2}$ and below 1.000 in $R M S E$.

\section{Table 4}

Comparison of apparent activation energies $\left(E_{a}\right)$ and coefficients of determination $\left(R^{2}\right)$ of regression lines calculated from the Arrhenius equation.

\begin{tabular}{lll}
\hline & $E_{a}[\mathrm{~kJ} / \mathrm{mol}]$ \\
\cline { 2 - 3 } & autocatalytic & best fit* (TTSP) \\
\hline$L^{*}$ & 106 & 125 \\
$a^{*}$ & 125 & 124 \\
$b^{*}$ & 113 & 118 \\
$\Delta E^{*} a b$ & 101 & 120 \\
\hline
\end{tabular}

* Eq. (14) was used as a best-fit model. 
Matsuo et al. (2012) Journal of Wood Science, 58(2), 113-119, Authors' copy

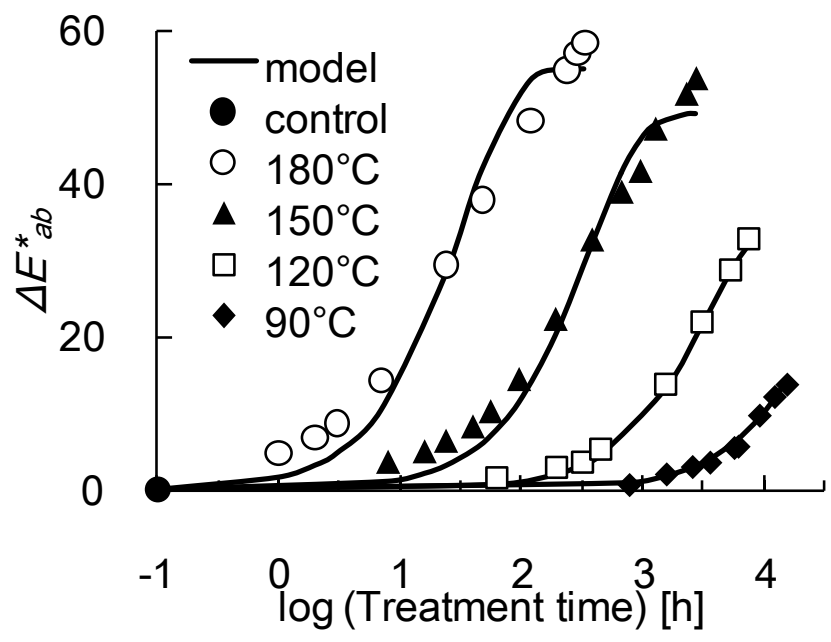

Figure 3

Change in $\Delta E^{*}{ }_{a b}$ and its model: autocatalytic model fitted to each temperature.

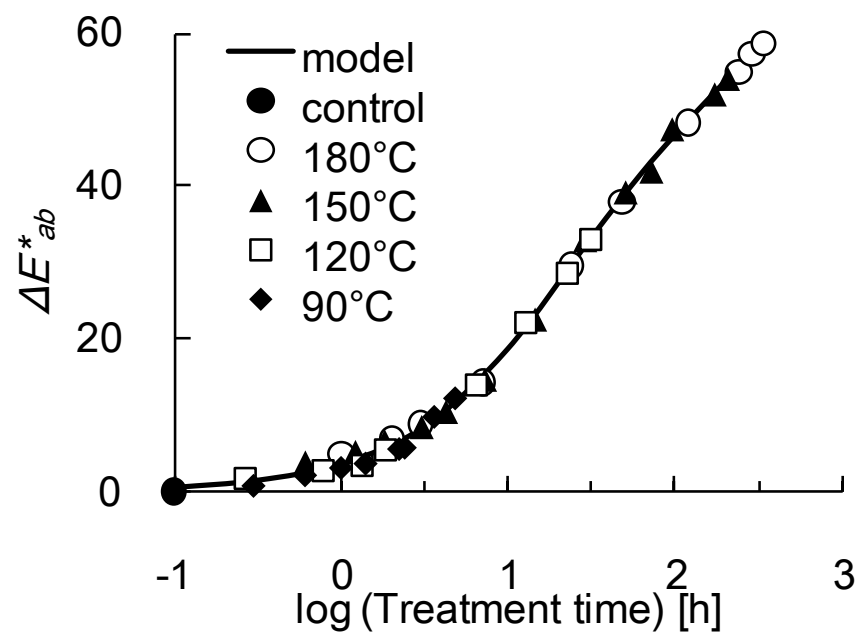

Figure 4

Change in $\Delta E^{*}{ }_{a b}$ and its model: best-fit model and superposed data by using $a_{T}$ at each temperature. 
Matsuo et al. (2012) Journal of Wood Science, 58(2), 113-119, Authors' copy

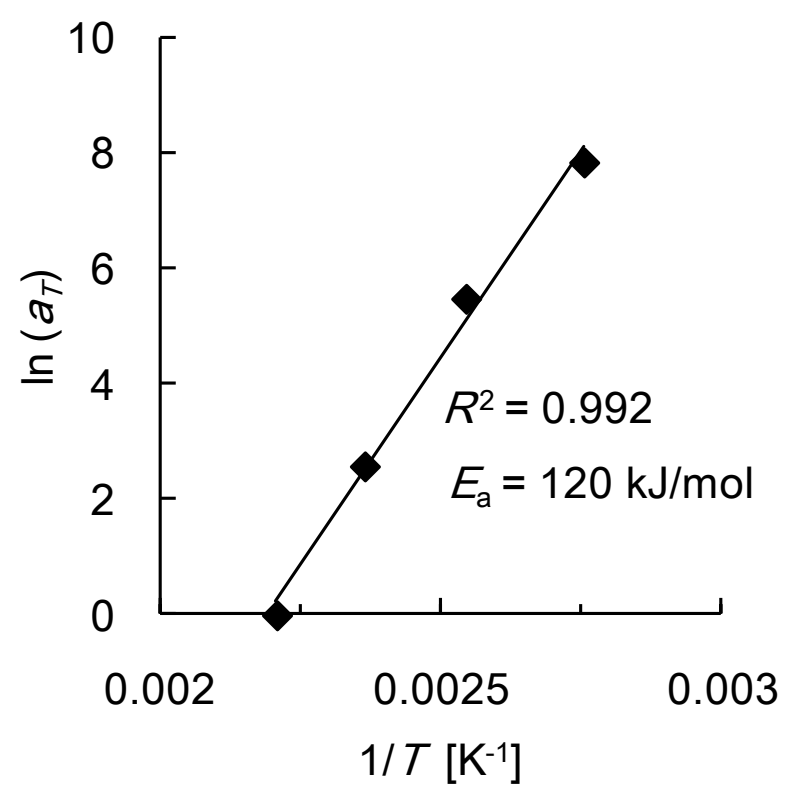

Figure 5

Arrhenius plots of the change in $\Delta E^{*}{ }_{a b}$ by using the best-fit model (Eq. 14) and TTSP method.

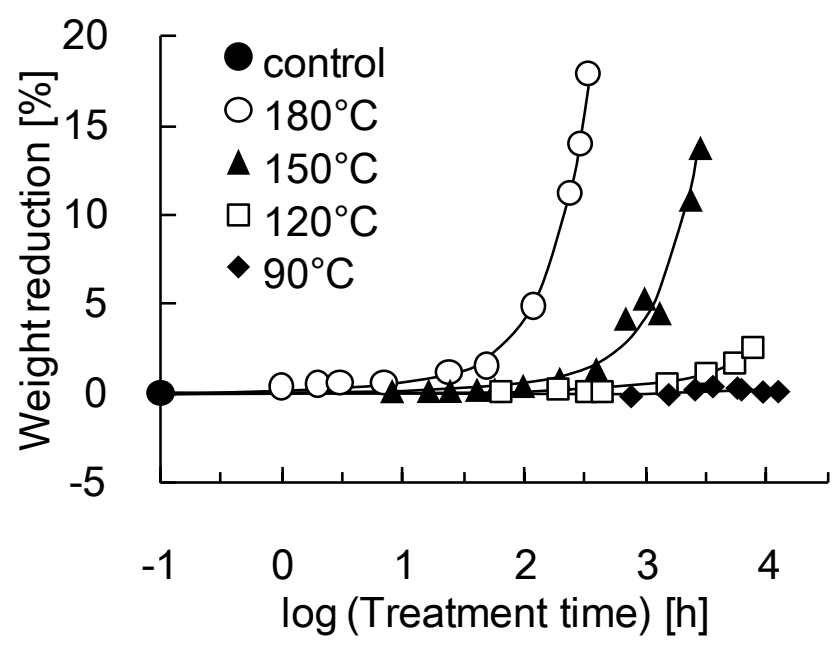

\section{Figure 6}

Weight reduction during heat treatment as a function of time. 


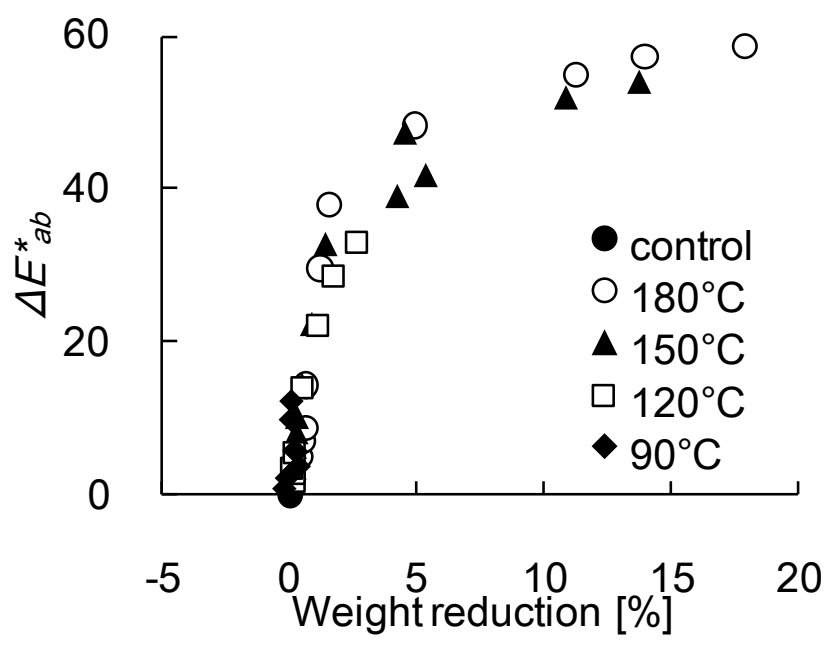

\section{Figure 7}

The relationship between $\Delta E^{*}{ }_{a b}$ and weight reduction.

\section{Conclusions}

Color changes of cellulose heated at $90-180^{\circ} \mathrm{C}$ were measured and expressed by CIELAB color parameters. The value of $L^{*}$ decreased and the values of $a^{*}, b^{*}$ and $\Delta E^{*}{ }_{a b}$ increased during heat treatment at all the temperatures. Among the several kinetic models applied to the experimental data, the autocatalytic model best explained the changes in all color parameters. However, according to the fitting of the autocatalytic model and a review of the results in the literature, it is concluded that color changes during heating could not be explained by an autocatalytic reaction. In order to accurately predict the color changes during heat treatment, it was better to use the best-fit model with the TTSP method. The Arrhenius plot showed good linearity in the best-fit model, implying that the color changes might be induced by the same mechanism at the temperature range from $90^{\circ} \mathrm{C}$ to $180^{\circ} \mathrm{C}$. The apparent activation energies calculated from color parameters by using the TTSP method ranged from 118 to $125 \mathrm{~kJ} / \mathrm{mol}$, which are similar to the reported values obtained from other chemical and mechanical properties of lingo-cellulose materials.

\section{Acknowledgements}

This work was supported by Grants-in-Aid for Scientific Research (A) (No. 20248020) and for JSPS Fellows (No. 21·2994).

\section{References}

1. Ali M, Emsley AM, Herman H, Heywood RJ (2001) Spectroscopic studies of the ageing of cellulosic paper. Polymer 42:2893-2900

2. Emsley AM, Stevens GC (1994) Kinetics and mechanisms of the low-temperature degradation of cellulose. Cellulose 1:26-56 
Matsuo et al. (2012) Journal of Wood Science, 58(2), 113-119, Authors' copy

3. Erhardt D, Tumosa CS (2005) Chemical degradation of cellulose in paper over 500 years. Restaurator 26:151-158

4. Zou X, Uesaka T, Gurnagul N (1996) Prediction of paper permanence by accelerated aging I. Kinetic analysis of the aging process. Cellulose 3:243-267

5. Zou X, Uesaka T, Gurnagul N (1996) Prediction of paper permanence by accelerated aging II. Comparison of the predictions with natural aging results. Cellulose 3:269-279

6. Zou X, Gurnagul N, Uesaka T, Bouchard J (1994) Accelerated aging of papers of pure cellulose mechanism of cellulose degradation and paper embrittlement. Polym Degrad Stabil 43:393-402

7. Müller M, Murphy B, Burghammer M, Riekel C, Pantos E, Gunneweg J (2007) Ageing of native cellulose fibres under archaeological conditions: textiles from the Dead Sea region studied using synchrotron X-ray microdiffraction. Appl Phys A-Mater 89:877-881

8. Zervos S, Moropoulou A (2006) Methodology and criteria for the evaluation of paper conservation interventions - A literature review. Restaurator 27:219-274

9. Łojewski T, Sawoszczuk T, Łagan JM, Zięba K, Baranski A, Łojewska J (2010) Furfural as a marker of cellulose degradation. A quantitative approach. Appl Phys A-Mater 100:873-884

10. Vives JMG, Escoda JRM, Guerra RA, Hernandez LA (2001) A method for the non-destructive analysis of paper based on reflectance and viscosity. Restaurator 22:187-207

11. Yatagai M, Zeronian SH (1994) Effect of ultraviolet light and heat on the properties of cotton cellulose. Cellulose 1:205-214

12. Shimazu F, Sterling C (1966) Effect of wet and dry heat on structure of cellulose. J Food Sci 31:548-551

13. Zervos S, Moropoulou A (2005) Cotton cellulose ageing in sealed vessels. Kinetic model of autocatalytic depolymerization. Cellulose 12:485-496

14. Stamm AJ (1956) Thermal degradation of wood and cellulose. Ind Eng Chem 48:413-417

15. Isogai A (2003) Science of cellulose (in Japanese). Asakura Publishing Co., Ltd., Tokyo

16. Selli E, Beltrame PL, Testa G, Bonfatti AM, Rossi E, Seves A (1998) Kinetic studies on the accelerated aging of cellulosic materials. Angew Makromol Chem 257:63-69

17. Kolar J, Strlič M, Marinček M (2002) IR pulsed laser light interaction with soiled cellulose and paper. Appl Phys A-Mater 75:673-676

18. Zhang YHP, Lynd LR (2005) Determination of the number-average degree of polymerization of cellodextrins and cellulose with application to enzymatic hydrolysis. Biomacromolecules 6:1510-1515

19. Japanese Industrial Standard Committee (2008) JIS Z 8729 Colour specification-CIELAB and CIELUV colour spaces (in Japanese)

20. Japanese Industrial Standard Committee (2009) JIS Z 8730, Colour specification-Colour differences of object colours (in Japanese)

21. Ding HZ, Wang ZD (2008) On the degradation evolution equations of cellulose. Cellulose $15: 205-224$ 
Matsuo et al. (2012) Journal of Wood Science, 58(2), 113-119, Authors' copy

22. Calvini P, Gorassini A, Merlani AL (2008) On the kinetics of cellulose degradation: looking beyond the pseudo zero order rate equation. Cellulose 15:193-203

23. Atkins P, Paula J (2010) Atkins' Physical Chemistry, 9th edn. Oxford University Press, New York 24. Ding HZ, Wang ZD (2007) Time-temperature superposition method for predicting the permanence of paper by extrapolating accelerated ageing data to ambient conditions. Cellulose 14:171-181

25. Gillen KT, Clough RL (1989) Time-temperature-dose rate superposition: A methodology for extrapolating accelerated radiation aging data to low-dose rate conditions. Polym Degrad Stabil 24:137-168

26. Wise J, Gillen KT, Clough RL (1995) An ultrasensitive technique for testing the Arrhenius extrapolation assumption for thermally aged elastomers. Polym Degrad Stabil 49:403-418

27. Gillen KT, Celina M (2001) The wear-out approach for predicting the remaining lifetime of materials. Polym Degrad Stabil 71:15-30

28. Barański A (2002) Ageing kinetics of cellulose and paper. Restaurator 23:77-88

29. Agrawal RK (1985) On the use of the Arrhenius equation to describe cellulose and wood pyrolysis. Thermochim Acta 91:343-349

30. Łojewska J, Missori M, Lubańska A, Grimaldi P, Zięba K, Proniewicz LM, Castellano AC (2007) Carbonyl groups development on degraded cellulose. Correlation between spectroscopic and chemical results. Appl Phys A-Mater 89:883-887

31. Matsuoka S, Kawamoto H, Saka S (2011) Thermal glycosylation and degradation reactions occurring at the reducing ends of cellulose during low-temperature pyrolysis. Carbohyd Res 346:272-279

32. Matsuoka S, Kawamoto H, Saka S (2011) Reducing end-group of cellulose as a reactive site for thermal discoloration. Polym Degrad Stabil 96:1242-1247

33. Matsuo M, Yokoyama M, Umemura K, Gril J, Yano K, Kawai S (2010) Color changes in wood during heating: kinetic analysis by applying a time-temperature superposition method. Appl Phys A 99:47-52

34. Bekhta P, Niemz P (2003) Effect of high temperature on the change in color, dimensional stability and mechanical properties of spruce wood. Holzforschung 57:539-546

35. González-Peña MM, Hale MDC (2009) Colour in thermally modified wood of beech, Norway spruce and Scots pine. Part 1: Colour evolution and colour changes. Holzforschung 63:385-393 